\title{
Exploring happiness: From Aristotle to brain science
}

\author{
Sissela Bok, Yale University Press, 2010, ISBN: 978-0-300-1329-7 (cloth), 224pp \\ Sissela Bok, Yale University Press, 2011, ISBN: 978-0-300-17810-4 (paper), 224pp
}

\author{
Review by \\ Richard D. Parry
}

Exploring Happiness does what its title indicates by covering a wide range. Sissela Bok's first aim is to bring together "the striking new findings of natural and social scientists with longstanding traditions of reflection by philosophers, religious thinkers, historians, poets, and so many others." (p. 3). Throughout, she offers sketches of various positions in such a way as to encourage the reader to compare and contrast; rather than giving much in the way of detailed suggestions for putting the pieces together, she emphasizes the value of competing theories and insights. The second aim is to reflect on the relation between happiness, understood as an individual pursuit, and morality, i.e., the way we treat others. The latter effort offers one important counter-weight to the dangers of spending too much time absorbed in one's own welfare; but it also introduces one of the most complicating factors in the whole attempt to think about happiness.

The book is aimed at an informed but general audience. Treating such an important but elusive topic as happiness at this level is, of course, commendable. And Bok delivers a lot of clear and readable prose that informs us of a wide and deep company of thinkers. We find not only philosophers but also writers from other disciplines. It appears that a lot of our cultural luminaries could not keep themselves from offering their own reflections on happiness. Not only does she present them for our appreciation but also she does a good job of pointing up the interesting ways in which they differ from one another, not only in content but also in approach. We go from descriptions of experiences of happiness to theories about the concept, to contemporary research on what people in general report about their own happiness. Along the way, we are given helpful, if not altogether surprising, advice about respecting, while being appropriately skeptical about, the various perspectives. One can imagine the general reader being delighted to find all this material in one place, marshalled for her appreciation. And for the specialist, there is great value in having one's disciplinary horizons opened a bit. While a reviewer should respect the constraints that such an undertaking imposes, there is, nevertheless, room for reflection and dialectic.

One of the most important issues that Bok touches on is the relation between happiness as experience and happiness as an objective state. She begins with some descriptions of those exalted states so often held to be paradigm cases of happiness. In doing so, she feeds into what most contemporary people believe about happiness; it is to be identified with a certain kind of feeling. In English, if you ask someone if she is happy, the answer will usually involve a 
reference to one's feelings. One might described her current emotional state or the way she feels about her life in general. Answers like these are not, of course, wrong in themselves. However, they risk reducing happiness to states of positive feeling. Bok, then, raises the obvious objection to such reductionism with Robert Nozick's famous Experience Machine. If they were given a choice between being hooked up to a machine that provided a consistent diet of pleasant feeling and living a real life, with its ups and downs, most people would choose the latter. The point is not the number of people who would choose the lived-life; rather the argument shows that there is a conceptual difference between experiences of pleasure, or positive emotion, and happiness. If there were no difference, the choice would not make any sense. Since there is a difference between the subjective feeling of happiness and the objective state on which the feelings are based, one might say that there is an inside and an outside to happiness.

This issue is more than a conceptual puzzle. It touches on one of the most important issues that Socrates, Plato, and Aristotle ever raised. If happiness is an objective state about which we can be wrong, then living a life in which we never attain that state, because of ignorance, is a tragedy. Nothing is more important than one's happiness not because it is some positive emotional state but because it is the best possible state that one can achieve. According to the ancients, this state is what we would call a psychological one. Lest, at this point, we fall back into a hedonist conception of psychological state, we need to recognize that these thinkers were trying to describe something like an Olympic athlete of the soul-one whose psychological powers, e.g., reasoning and emotion, are fully developed and in perfect sync with one another. Then whatever he did-fighting in battle, ruling the city, treating fellow citizens, scientific investigation - would be splendid. While they called this state arête, sometimes translated as virtue, it is not reducible to moral virtue, although it certainly implies it. The most appropriate translation of arête is excellence.

This identification of happiness with psychological excellence has another powerful implication. It forges the link between happiness and morality. In doing so, the ancients were trying to address the problem that some immoral people appear to be happy. They are happy not just in their external circumstance, i.e., prosperous; but they lead lives filled with pleasure and satisfaction. They can even be said to have satisfied all their major life goals. Plato, especially, is consumed by this problem. His answer depends on the idea of psychological excellence. The backbone of this argument is that the excellent functioning of the soul would manifest itself as morally virtuous activity, i.e., as justice, courage, and moderation. That one would be pleased with this activity is important; but it is not central to the argument that linked psychological excellence and moral virtue. That the evil tyrant felt satisfied with his life only meant that he was deceived about the disarray in his soul. Sound or not, this is an argument aimed directly at the usual objection that some evil people enjoy a positive emotional life, are happy in the sense that they feel happy.

Although she recognizes the distinction, unfortunately Bok does not clearly demarcate the subjective from the objective side of happiness. Those who labor in these vineyards sometimes make the distinction between happiness as a subjective feeling and happiness as an objective state of wellbeing, or flourishing. Perhaps in a book for the general reader that level of analysis is not appropriate. Still, without it, we are left with the impression that happiness is really a feeling. Throughout the rest of the book we keep running into descriptions of happiness as an emotion, as a pleasure, as a positive feeling. The overarching problem of the book, then, becomes, given that happiness is basically a subjective feeling, how can we reconcile this feeling with objective constraints. This weakness undermines the second aim announced for the 
book, the problem of the relation between happiness and morality. If happiness is basically a positive feeling, there is no escaping the fact that some scoundrels are happy. As a consequence, Bok's treatment of it effectively ends in Chapter III with her overview of Kant's separation of happiness and morality, the latter described as the rational being's consciousness of the pleasantness of life. She leaves us with the somewhat disappointing conclusion that recent research shows some correlation between altruism and subjective wellbeing.

To her credit, Bok tries to do justice to the religious thinking on the topic of happiness, much of it dependent on the afterlife. Since she does little to explain the idea-understandably perhaps - these sections can speak only to people already with a religious understanding. However, she does give us a juicy clue. As she points out, Aquinas makes a distinction between happiness as felicitas and as beatudo, the former possible in earthly existence and the latter available only in heaven. Another reading would have taken this opportunity to offer some plausibility to the happiness of the afterlife. Felicitas can be translated as happiness and beatudo as blessedness. In ancient Greek thought, they meant roughly the same thing. Aquinas distinguishes them along a natural/supernatural axis. Felicitas covers, more or less, the kind of happiness that Aristotle would call virtuous activity of the soul; but beatudo is the vision of God, i.e., the beatific vision, the kind of seeing that makes one blessed. It has resonance with Aristotle's other account of happiness as virtue, i.e., contemplation of eternal truths. From these clues we arrive at a notion of an afterlife as a heightened state of awareness which transcends the ordinary categories of time and space. This result fits nicely with Bok's citations of other religious thinkers who identify eternal happiness with contemplation.

In the chapter on measurement, Bok brings to bear much of what she has to say about psychological and sociological research on happiness. One type of investigation involves imaging, to identify the areas of the brain associated with self-reported positive and negative emotional states. The other uses surveys of large populations about their self-reported states of happiness. She points out that both offer some interesting data that sometimes confirm and other times disconfirm what earlier thinkers have said about happiness. She only touches on the brain research, as offering important empirical data about the pervasiveness of pleasure and pain throughout other mental states. She devotes more attention to the social science research about happiness. Social psychologists have devised questionnaires that gather data on self-reports of satisfaction with one's life. These studies have provided very interesting results for anyone approaching the topic of happiness. However, Bok points out their limitations as the basis for a science of happiness. For instance, there is the direction of causation. If most married people report being satisfied with their lives, it is not clear whether marriage causes the satisfaction or people who are generally satisfied with their lives are more likely to get married. She also touches on the cultural bias that can result in a difference in response between, for example, Americans and Europeans. The issue of cultural bias suggests a more profound problem. Since so much of the research relies on self-reporting, we are left with a great skeptical gap. Just because large numbers of people within a culture report satisfaction with their lives, or report having positive feelings on doing the same activity, it does not follow that they are happy. Only if one assumes that happiness is the same thing as a state of positive feeling - as much of this research seems to-can one arrive at this conclusion. Bok helpfully refers the reader to thinkers who have explored the relation between social science research and philosophy, such as Anthony Appiah, Owen Flanagan, and Daniel Haybron.

Finally, Bok treats of the fascinating problem about happiness illusion. There are famous cases in which individuals profess to be happy, in the sense of feeling happy, when their objective state would not be counted as happiness by anyone observing them. The problem has 
many guises, from naïve ignorance to false consciousness. On the one hand, there are those who argue that happiness cannot be based on illusion; no matter how upbeat, pleased, or satisfied one might be, the facts must fit with whatever she claims. On the other, there are those who argue that happiness is to be identified with one's positive emotional state, whatever the facts may be. Bok cites Madame du Châtelet as someone who argues for the appropriateness of illusions that contribute to one's happiness. In her own life, she held tenaciously to the belief that Voltaire's love for her was continuing. When she could no longer maintain that illusion, she turned to gambling. She argued that the hope of winning and the fear of losing could be managed as parts of an elaborate illusion-like the opera-as long as one could keep the gambling under control. Since, in fact, she did not keep it under control, Bok suggests her life shows the weakness of her argument. Even so, the basic issue is not settled. While illusions of happiness can be self-destructive, as long as the illusion holds, those dedicated to the idea that happiness is a positive state of feeling can discount the self-destruction as collateral damage. Bok's argument works only for those who already accept the difference between illusion and happiness.

This valuable book presents us with a lot of rich material for thought. Bok manages extremely well the difficult task of arranging divergent views so that they provoke the reader to further dialectic and continued exploration. It is certainly a welcome contribution to recent work in the study of happiness.

\section{Author}

Richard D. Parry

Agnes Scott College

rparry@agnesscott.edu 